\title{
SATURNINO DE BRITO E O PROJETO DE ABASTECIMENTO DE ÁGUA PARA A CIDADE DE PASSO FUNDO-RS
}

\author{
Dirceu Piccinato Junior ${ }^{1}$
}

DOI: 10.5752/P.2316-1752.2017v25n36p16

\section{Resumo}

O início do século XX é marcado por reformas sanitaristas no Brasil. Com a industrialização e a modernização das cidades, a ideia de progresso se sobrepõe à tradição e o crescimento das cidades favorece o debate sobre como deveria ser o desenvolvimento delas. Muitas cidades brasileiras vão ser pensadas sob a perspectiva do urbanismo sanitarista do engenheiro Francisco Saturnino Rodrigues de Brito. Sob a perspectiva desse urbanismo, o objetivo deste artigo é analisar e compreender o projeto de abastecimento de água para a cidade de Passo Fundo, norte do estado do Rio Grande do Sul.

Palavras-chave: Saturnino de Brito. Urbanismo sanitarista. Projeto. Abastecimento de água. Passo Fundo/RS.

\footnotetext{
1. Arquiteto e Urbanista pelo Centro Universitário Moura Lacerda. Doutor em Urbanismo pelo Programa de Pós-Graduação em Urbanismo da Pontifícia Universidade Católica de Campinas. Docente do Programa de Pós-Graduação Stricto Sensu em Arquitetura e Urbanismo e da Faculdade de Arquitetura e Urbanismo da Faculdade Meridional - IMED, Passo Fundo, estado do Rio Grande do Sul; e-mail: dirceu.piccinato@imed.edu.br
} 


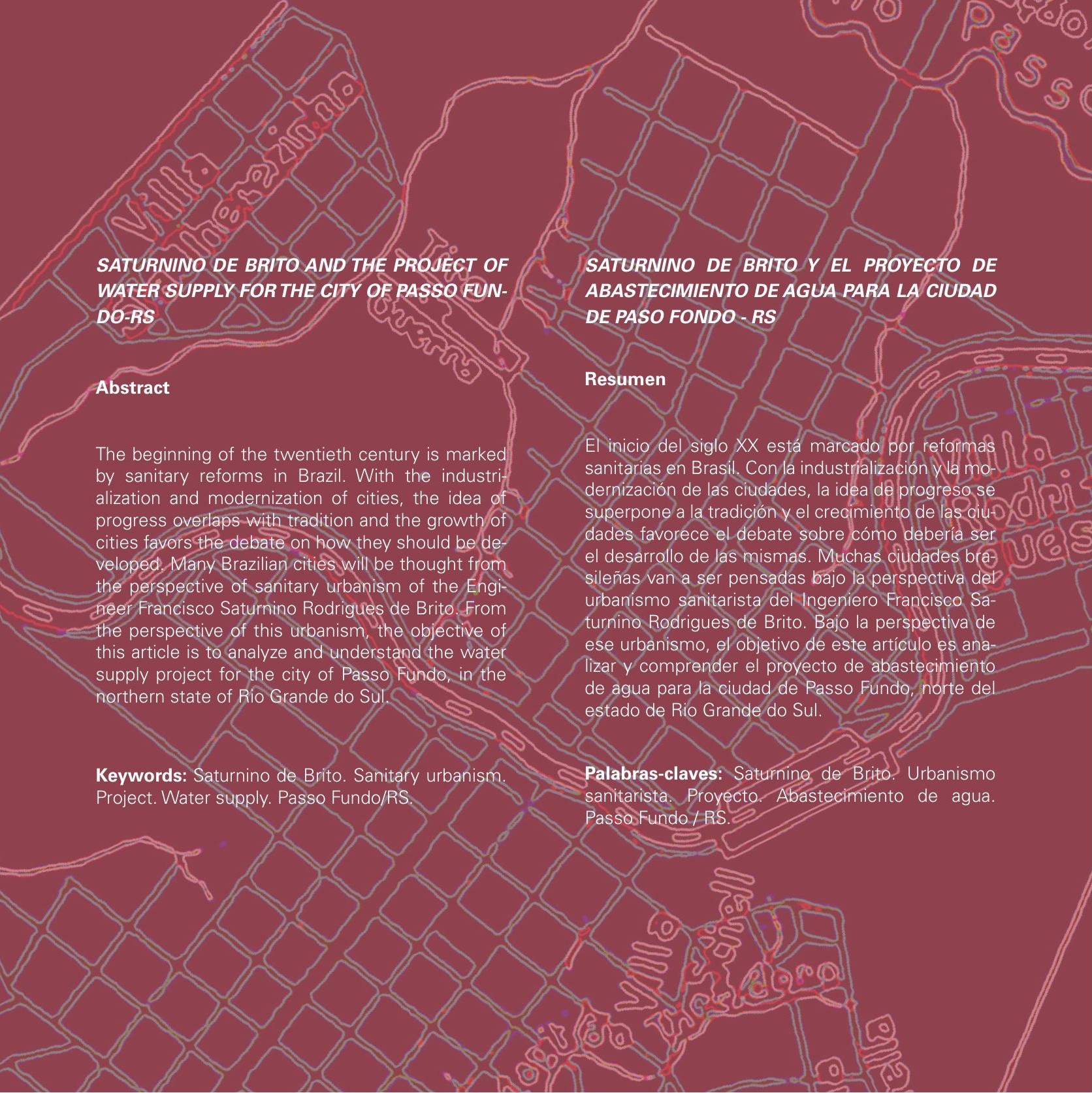




\section{Introdução}

$\mathrm{Na}$ história das civilizações, de modo geral, os cursos d'água, rios, córregos, riachos integravam sítios atraentes para assentamentos de curta ou longa permanência, indistintamente, e eram considerados como marcos ou referências territoriais. No imaginário coletivo, figuram predominantemente associados aos mananciais, porém apresentam propriedades outras, como demarcadores de território, produtores de alimentos, corredores de circulação de pessoas e de produtos comerciais e industriais, corredores de fauna e flora, geradores de energia, espaços livres públicos de convívio e lazer, marcos importantes de caráter turístico e elementos determinantes na constituição de feições geomorfológicas (GORSKI, 2010).

Com a evolução da urbanização, foi-se conseguindo anular sua importância, restringindo sua presença nas cidades apenas como sintomas perturbadores do bem-estar urbano, ou seja: mau cheiro, lixo, transtornos em dias de chuvas, obstáculo à circulação e ameaça de inundações. Chega a parecer que os corpos d'água se apresentam de forma inerente ao desenvolvimento dos espaços urbanos.

O processo de urbanização, ocorrido particularmente a partir das primeiras décadas do século $X X$, em razão dos fluxos migratórios advindos da área rural e aos movimentos 
intraurbanos, exerceu significativa pressão sobre as áreas urbanas, em especial sobre as metrópoles. A concentração populacional no meio urbano, em um cenário marcado pela carência de investimentos em planejamento e infraestruturação urbana, desencadeou um processo de perda de qualidade de vida urbana. "No tocante aos padrões ambientais, resultou em água, ar, solo e vegetação impactados e em franca deterioração" (GORSKI, 2010, p. 61).

Um dos principais problemas relacionados à degradação dos rios e mananciais, seja em função do processo de urbanização ou não, é a escassez qualitativa da água enquanto fonte de vida e manutenção do desenvolvimento da sociedade.

Na medida do crescimento industrial e demográfico das cidades, o desenvolvimento das formas de controle das águas se tornou central para a vida urbana moderna e, a partir do final do século XIX, essa relação entre o homem e a água foi cada vez mais mediada por saberes e equipamentos associados à engenharia sanitária. Os cuidados de aferição da qualidade dos corpos d'água, as obras de canalização, o represamento e a drenagem das várzeas de rios instauraram um movimento de racionalização do comportamento dos recursos hídricos no espaço urbano. A água, nesse momento, assumiu um sentido paradoxal, ou seja, ao mesmo tempo em que se tornou vital para a 
vida urbana, ela passou a ser vista como foco de doenças e causadora de transtornos urbanos (DEMINICI, 2015).

Os recursos hídricos de uma cidade foi eixo ordenador do delineamento do espaço urbano e também um obstáculo a ser transposto. Todavia, atualmente a sociedade considera esses recursos como um bem vital para as futuras gerações. Muitas cidades estão pensando, discutindo e elaborando projetos para melhorar o sistema de captação e distribuição da água, considerando a preservação e renovação de suas fontes.

Nos últimos anos, em particular neste ano de 2018, o noticiário local, regional e até mesmo estadual vêm veiculando notícias sobre a Companhia Riograndense de Saneamento (CORSAN), unidade Passo Fundo, estar estudando e elaborando novas políticas e projetos para ampliar a captação de água na cidade de Passo Fundo. Uma razão desse movimento é a preocupação ambiental na cidade, já que, por exemplo, a área para ampliação do aeroporto de Passo Fundo é formada por pequenas nascentes que configuram as bacias hidrográficas dos rios Passo Fundo, Alto Jacuí, Apuaê-Inhandava e Taquari-Antas.

No começo do século XX, sob o pensamento positivista, os políticos da época contrataram o engenheiro Saturnino de Brito para desenvolver inúmeros planos de melhoramentos 
urbanos para diferentes cidades do estado. Dentre essas cidades, destaca-se Passo Fundo. Brito desenvolveu um projeto de saneamento urbano para a cidade no ano 1919, composto por diferentes aspectos do espaço urbano e rural, e um tópico estudado e projetado pelo engenheiro foi o abastecimento de água para a cidade. Para tanto, como justificativa deste presente artigo, pondera-se que se o projeto tivesse sido implementado, hoje os problemas com a hidrologia superficial de Passo Fundo possivelmente seriam menores.

Como hipótese, argumenta-se que o projeto de abastecimento de água para a cidade de Passo Fundo, elaborado por Saturnino de Brito, revela, desde essa época, uma preocupação com as questões ambientais intrínsecas à própria cidade e sensibilidade na percepção de elementos da paisagem que poderiam (ou deveriam) ter sido preservados e apropriados no processo de urbanização e saneamento, constituindo em uma construção sustentável da cidade. Portanto, o objetivo principal é analisar o plano de melhoramentos urbanos de Saturnino de Brito para Passo Fundo, sob a dimensão do urbanismo sanitarista.

Como procedimento metodológico, ressalta-se a interlocução entre a fonte documental primária (o relatório e o plano de melhoramentos urbanos de Brito) e as referências bibliográficas que debatem acerca do urbanismo sanitaris- 
ta de Saturnino de Brito, hidrologia e sustentabilidade. No intuito de caracterizar as discussões e resultados, o artigo está estruturado em partes: na primeira parte, busca-se compreender o ideário urbano de Saturnino de Brito; na segunda parte, o projeto de Saturnino de Brito é analisado e debatido, conferindo atenções especiais aos recursos hídricos da cidade de Passo Fundo; por fim, têm-se os resultados do estudo, isto é, as considerações finais ponderando que o engenheiro procurou aliar no projeto saneamento, embelezamento e proteção do patrimônio natural presente em Passo Fundo, denotando a relevância deste trabalho.

\section{O urbanismo sanitarista de Saturnino de Brito}

Com o período republicano no Brasil, intensificou-se a formação de um mercado de trabalho livre e o esforço construtivo destinado à construção de um território organizado dentro dos mais atuais, à época, referenciais socioeconômicos e culturais impostos, os quais cresciam e se aprofundavam. Associados à permanência do imigrante que começava a chegar em terras nacionais e à transformação das cidades, os programas de saneamento tornaram prioridade no início da República (GITAHY, 2005, p. 1). Foram projetados e construídos diversos serviços de abastecimento de água, canais de drenagem e esgotos.

O progresso científico na área das ciências da saúde con- 
tribuiu, dentro da realidade nacional a partir da segunda metade do século XIX, para a adoção dos princípios do sanitarismo nas práticas urbanas, em um momento em que o enfrentamento das epidemias exigia que as áreas centrais fossem remodeladas, de forma a implantar serviços de infraestrutura de água e esgotos, a sanear áreas pantanosas e inundáveis, a prover espaços públicos abertos para facilitar a aeração e a insolação, a eliminar focos de concentração de moradias não salubres, os cortiços, e a estabelecer regulações para as construções no espaço urbano (SIMÕES JUNIOR, 2013, p. 125).

As cidades eram consideradas insalubres, com sujeira pelas vias, ruas esburacadas e alagadiças em dias chuvosos. As doenças geradas pela falta de higiene e saneamento causaram a morte de muitos cidadãos. $\mathrm{O}$ esgoto in natura circulava pelos logradouros juntamente com o cidadão. $O$ mau cheiro acompanhava os moradores. A água para consumo ficava distante das moradias. A iluminação à noite era precária ou ausente em muitas realidades à época. O traçado urbano desenvolvido na maioria das cidades dificultava a vida de seus moradores. É em meio a essa realidade que o engenheiro sanitarista Saturnino de Brito atuou por meio de seus planos de melhoramentos.

No ano de 1881, Brito ingressou na Escola Politécnica do Rio de Janeiro, onde se formou em Engenharia Civil em 
1886. De 1887 a 1892, exerceu seu primeiro emprego como engenheiro civil, na estrada de Ferro Leopoldina. Em 1893, interrompeu sua carreira, por um ano, para servir à causa do governo legal como voluntário. No ano 1894, restabeleceu sua vida profissional como Engenheiro da Carta Cadastral do Rio de Janeiro e, no ano seguinte, fez o levantamento das plantas e organização dos projetos de saneamento da cidade de Vitória, estado do Espírito Santo. Em 1896, trabalhou como Engenheiro da Comissão de Saneamento do estado de São Paulo. A partir de 1898, passou a realizar inúmeros trabalhos para as mais diferentes cidades do Brasil. Sua atuação profissional percorreu ao todo $53 \mathrm{ci-}$ dades brasileiras, onde pôde expor suas ideias e particularmente aplicá-las na área de saneamento e embelezamento das cidades (LEME (coord.), 1999, p. 454-455).

Foi em meio a esse processo de modernização nacional que se firmaram algumas influências que nortearam as operações de melhoramentos e ideário urbanos. Em relação a Saturnino de Brito, pode-se observar sua proximidade com a escola francesa de urbanismo.

Angelo Bertoni (2015, p. 82) destaca que o trabalho de Camillo Sitte foi muito importante para Saturnino. As ferramentas de análise desenvolvidas por Sitte na sua obra Construção das cidades segundo seus princípios artísticos foram compreendidas por Saturnino para apoiar a demons- 
tração de uma colaboração importante entre técnicos e urbanistas. O estabelecimento de um plano geral era essencial para nortear o crescimento ordenado das cidades, isto é, o primeiro elemento a se considerar era a definição das redes técnicas, que deveriam tirar proveito de encostas naturais para reduzir os custos de implementação, ou seja, a definição de uma topografia sanitária. Bertoni acrescenta ainda que Brito demonstrou uma profunda sensibilidade e experiência ao debater sobre a questão da linha reta e curva das ruas, lembrando que os efeitos pitorescos não poderiam ser considerados em detrimento da eficácia sanitária.

Ao analisar a obra de Saturnino de Brito, o livro Notes sur le tracé sanitaire des villes (Notas sobre o traçado sanitário das cidades), escrito em francês, Angelo Bertoni (2015, p. 81) elucida que a compreensão do urbanismo sanitário de Brito tinha como desígnio dois temas: os problemas de salubridade na transformação dos espaços urbanos e a construção das cidades; as competências profissionais e o diálogo entre as ciências. A abordagem defendida por Saturnino de Brito estava fundamentada na engenharia sanitária, sua ciência de referência, mas ele ampliou o ideário para além do saneamento urbano ao projetar intervenções em áreas urbanas existentes e a serem formadas.

Outra conjuntura a ser contextualizada, não só no pensamento de Saturnino de Brito, é que a preocupação com a 
salubridade acabou por induzir a introdução de novos espaços arborizados e livres na configuração física das cidades, considerados de suma importância para a saúde da população. No sentido de associar materialmente essa preocupação, acabaram emergindo diferentes programas de conservação dos parques existentes e obras de reforma viária das áreas centrais, que imprimiram novos cenários, novos usos e novas sociabilidades no espaço intraurbano de várias cidades brasileiras (TOCHETTO, 2013, p. 42).

O traçado da cidade moderna, saneada, deveria ser configurado conforme suas necessidades, não copiando o traçado das cidades antigas, mas tomando-as como fonte de inspiração.

Para Daniel Tochetto (2013, p. 104-105), Saturnino de Brito definiu que a necessidade era a circulação, abrir ruas, criar avenidas, elementos incompatíveis com o desenho irregular das cidades antigas. As necessidades da vida moderna não poderiam mais se adaptar aos traçados irregulares da maioria das cidades antigas, pelo menos nos novos bairros. Algumas alterações eram pertinentes, como promover a abertura de espaços, alargamento de ruas e avenidas. No entanto, para suprir as necessidades da vida moderna, era preciso um plano de melhoramentos urbanos.

Entretanto, o plano que regularizaria a construção da cida- 
de, para ser efetivado, careceria de uma lei que o legitimasse, como acontece atualmente. Para, assim, sanear e modernizar o espaço urbano, "Brito implantará o planejamento urbano na administração de inúmeras cidades brasileiras" (ANDRADE, 1992, p. 4).

Além de planejar, embelezar e sanear as cidades tomadas ou sob ameaça de epidemias, o urbanismo sanitarista de Saturnino de Brito concedeu às cidades brasileiras um novo padrão estético, moderno e progressista, além de formas urbanas próprias de uma tecnologia de saneamento cuja implantação se tornou, durante toda a primeira república, um dos pilares do Estado Novo. André Luís Borges Lopes (2013, p. 77) complementa o discurso ao considerar que, a partir da consolidação da nova ordem republicana, as principais cidades brasileiras passaram por um processo de modernização e urbanização relacionados ao novo projeto político das elites no poder. Esse rearranjo espacial e social estava baseado em novos paradigmas de higienização e embelezamentos franceses.

Assim, as obras de infraestruturação e de melhoramentos urbanos do engenheiro Saturnino de Brito circunscrevem-se em um conjunto de operações em consideráveis escalas que redefiniram a paisagem urbana de diversas cidades brasileiras. 
Sobre a construção da paisagem pelo ideário urbano de Saturnino de Brito, Juliana Bandeira A. Burger (2008, p. 40) argumenta que os trabalhos de Brito expressavam a ideia de que uma cidade deveria ser moderna e funcional, enfatizando os princípios da racionalidade e funcionalidade latentes tanto nas obras de engenharia quanto nos projetos de arquitetura e paisagismo. As marcas deixadas por Brito na paisagem das cidades em que trabalhou promoveram o desenvolvimento partindo do entendimento das condições originais do sítio com a adaptação às necessidades de uma sociedade urbana. Sob essa perspectiva, sua intervenção na paisagem visava ao diálogo dos fenômenos naturais com as técnicas sanitaristas, considerando a cidade em toda a sua abrangência.

Na Engenharia Sanitária, pode-se considerar que a configuração topográfica, as áreas verdes e os recursos hídricos, com ou sem a interferência de obras perpetradas pelo homem, eram os elementos que comumente modelavam a paisagem. Mas esses fatores associados às articulações sociais e econômicas configuraram o quadro adequado para o desenvolvimento de um planejamento urbanístico e sanitário no país.

Saturnino de Brito defendia como tarefa fundamental de qualquer cidade a obrigação de prever a expansão da rede sanitária e dos arruamentos. Carlos Roberto Monteiro de 
Andrade (1992, p. 57) argumenta que o engenheiro afirmava que a necessidade de se elaborar planos gerais de expansão se dava por três fatores: evitar que o crescimento da cidade acontecesse ao acaso, extirpar os conflitos entre interesses privados e públicos e conceder maior longevidade às obras de saneamento, para que elas não fossem comprometidas no futuro.

Para Saturnino de Brito, o plano de melhoramentos urbanos deveria assumir a perspectiva de um plano geral, determinando os arruamentos futuros bem como regulando os arruamentos existentes. Todavia, a cidade era pensada como um todo. A preocupação com água, esgoto, habitação, traçado, área verde e topografia era pauta de análises e projetos.

Dentro desse contexto de planejamento geral desenvolvido por Brito, era fundamental realizar um levantamento prévio da cidade existente. Assim, Saturnino de Brito desenvolveu uma metodologia ampla para levantamentos e diagnósticos da área a ser estudada, importantes para a organização dos projetos: levantamento topográfico preciso, ruas e becos a serem alargados, locais pitorescos a serem preservados, áreas para jardins e parques, áreas para uma futura expansão da cidade, levantamentos cadastrais, características econômicas, planos e posturas municipais elaboradas anteriormente, população, vegetação, clima, 
salubridade, bem como causas de insalubridade, situação dos serviços urbanos, condições sanitárias, mananciais a serem preservados, natureza das águas, mensuração do volume de água requisitado, indicações precisas das condições de descarga dos despejos, atitudes da população do ponto de vista higiênico, condições das moradias, tipos de instalações nas residências e condicionantes topográficas (LOPES, 2013, p. 81).

Portanto, caberia ao engenheiro sanitário apresentar, em seus planos de melhoramentos urbanos, obras que demonstrassem adequadas condições para uma vida saudável, assegurando com suas construções as possibilidades de assegurar as higienes da água, do ar, do solo e do corpo.

A hidrologia superficial das cidades permitia que as águas concedessem valor à paisagem, introduzindo novos elementos de interesse visual. Tal circunstância caracterizava o fato de as obras de saneamento de uma cidade compreenderem, conforme a necessidade e realidade, no enxugamento das águas superficiais estagnadas; drenagem do subsolo das regiões pantanosas próximas, suprimento de água potável, entre outros cuidados com a água no meio urbano. A aquisição da salubridade urbana, nos planos de Saturnino de Brito, sempre esteve vinculada às reformas urbanísticas que incluíam intervenções significativas nas águas existentes na cidade. 
Marília de Azevedo Dieb (2015, p. 70-71), ao analisar as contribuições de Saturnino de Brito à leitura das águas urbanas brasileiras na construção da paisagem urbana e na proteção dos corpos d'água e recursos hídricos entre o final do século XIX e a primeira metade do século XX, revela que as intervenções propostas por ele tinham como marca incomum para a época: demonstração de sua preocupação com as questões ambientais intrínsecas a cada situação abordada; sensibilidade na percepção de elementos da paisagem que poderiam ou deveriam ser preservados e apropriados no processo de urbanização e saneamento de cada cidade; preocupação em informar e educar a população para as questões ambientais relativas ao meio urbano; o cuidado em nortear o adequado processo de expansão de cada localidade, por meio da elaboração de planos ou projetos urbanos, visando otimizar os investimentos feitos e evitar que todo o esforço dedicado ao saneamento e a qualidade urbana fosse comprometido depois, pela expansão sem planejamento. Com essa postura, Saturnino de Brito aliou ao saneamento o embelezamento das cidades onde atuou e a proteção (ao menos parcial) do patrimônio natural presente em cada uma delas.

Os estudos de Daniel Deminici (2015) sobre a utilização das águas do rio Pardo pela cidade de Ribeirão Preto, interior do estado de São Paulo, apontam que Saturnino de Brito foi um grande defensor da utilização de águas de rios para o 
abastecimento urbano da cidade. A cidade de Ribeirão Preto enfrentava um sério conflito entre a empresa que assumiu o serviço de abastecimento de água e o poder público, em função da qualidade da água servida. Para solucionar esse problema, Brito propôs a purificação das águas do rio Pardo, visando não comprometer o serviço, nem gerar doenças nos munícipes.

Muitos projetos e planos de melhoramentos urbanos foram desenvolvidos por Brito, entretanto, alguns se destacam frente as pesquisas acadêmicas. Não seguindo uma ordem cronológica, mas de exemplos que materializaram o ideário do engenheiro sanitarista, destaca-se o seu trabalho junto às cidades de Santos/SP e Vitória/ES.

Nas primeiras décadas do século XX, Santos tinha se tornado o principal porto de exportação de café, com a presença de postos de trabalhos atraídos pelas obras e serviços de infraestrutura realizada. Os cortiços, barracos construídos nos quintais dos casarões ou subdivisões em seus porões, eram as moradias que figuravam na paisagem da cidade. Doenças como a febre amarela, tuberculose, varíola e impaludismo (malária) acometiam a população de tempos em tempos. O agravamento das epidemias, que passaram a dificultar o comércio cafeeiro, tornou necessário controlar a produção do espaço e a vida cotidiana no sítio urbano, por meio da legislação e de intervenções no meio físico. No 
ano de 1905, Brito assumiu a Chefia da Comissão de Saneamento da cidade e nesse mesmo ano apresentou seu plano para o saneamento da cidade. Tinha como proposta adotar dois sistemas de separação absoluta e execução de uma extensa rede de canais de drenagem e galerias de esgotos, ao mesmo tempo em que o abastecimento de água se expandia (figura 1). A Santos moderna nascia estruturada em uma rede de infraestrutura suficiente para suportar o adensamento populacional da primeira metade do século XX (CARRIÇO, 2013, p. 159).

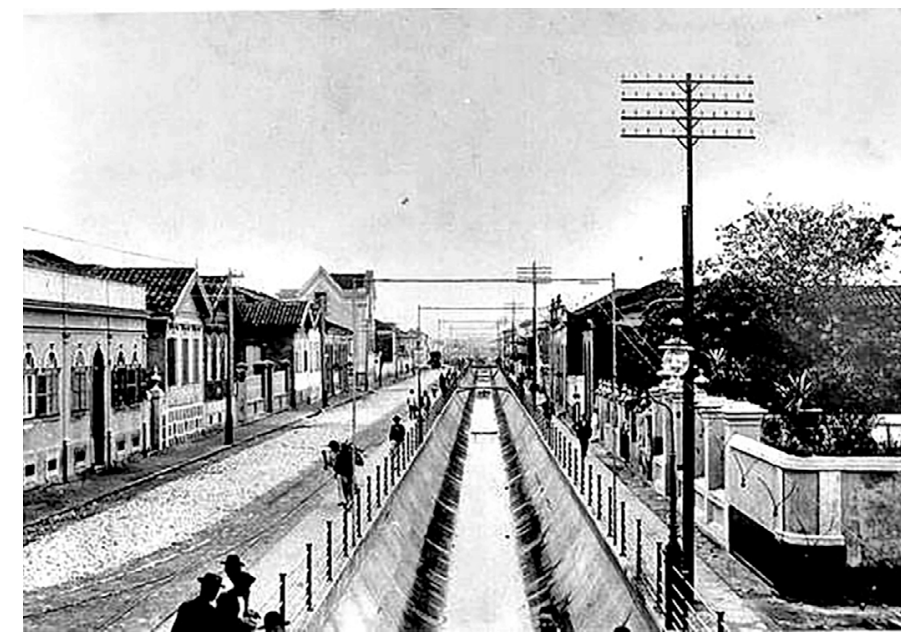

Figura 1 | Canal da rua Rangel Pestana, 1907, cidade de Santos. Fonte: Novo Milênio. Disponível em: <http://www.novomilenio.inf.br/santos/fotos071.htm>; acesso em: 29 set. 2018. 
Segundo Carlos Roberto Monteiro de Andrade (1991, p. 63), o plano de saneamento, melhoramentos e extensão que Saturnino de Brito elabora e implanta na cidade de Santos, mesmo não tendo sido implantado em todos os seus aspectos, não expressa apenas a construção de uma cidade moderna, mas também a aplicação de princípios urbanísticos revolucionários para o momento em que o passado colonial desapareceu em nome de um futuro marcado pela higiene e progresso, que influenciou decisivamente o desenvolvimento e o planejamento urbano no país.

Quanto aos esgotos, o projeto de Brito chamava a atenção dos sistemas estáticos (as fossas) e dinâmicos, dividido por ele em sistema sanitário, separados ou de canalização distinta e o sistema pneumático. Para Santos, defendeu o sistema pneumático, que funcionaria por meio das máquinas de aspiração e supressão. Considerava que a planta da cidade e de seus arrabaldes favorecia o projeto do sistema pneumático irradial. Acreditava ser possível utilizar os produtos do próprio esgoto da cidade para irrigação (BERNARDINI, 2015, p. 49).

O projeto elaborado por Saturnino de Brito para Santos buscava orientar e regular tanto a cidade construída como o processo de expansão. Ele empregou novas tecnologias sanitárias para solucionar a insalubridade do meio físico. A sua atuação na cidade, articulando o planejamento urbano 
e social, se configurou como uma importante contribuição ao planejamento urbano brasileiro realizado até então.

No ano de 1896, Saturnino de Brito desenvolveu o projeto de um novo arrabalde (bairro) dotado dos serviços de abastecimento de água e de drenagem para a cidade de Vitória, capital de estado do Espírito Santo. Inicialmente esse projeto apresentava um resumo justificativo das intenções do governo estadual com relação ao plano. A escolha do terreno para se implantar o novo arrabalde foi condicionada a dois fatores relacionados aos hábitos e situações econômica dos moradores da ilha de Vitória: localização próxima ao núcleo urbano da época, de modo que o transporte até o local fosse de fácil acesso, e o controle dos gastos. Esses determinantes convergiram para a região nordeste da ilha como local adequado (figura 2). A estrada de rodagem de ligação entre a cidade de Vitória e o novo bairro foi delineada considerando as possibilidades de construções às suas margens no futuro. O traçado do arruamento proposto por Saturnino de Brito para a área principal do projeto estruturava-se por meio de duas longas e retas avenidas, que cortavam diagonalmente uma malha retangular. $\mathrm{O}$ novo arrabalde era formado por 178 quarteirões e 2.129 lotes, dispostos em ruas com largura de 21 metros e avenidas de 28 metros, chegando em alguns casos a 35 metros de largura. Os lotes de 14 metros de frente e 42 metros de fundo foram dispostos no quarteirão de modo que cada 
edificação implantada seria contemplada por ventilação saudável, garantida pela abertura de janelas em todas as faces do edifício, em função dos amplos afastamentos de frente, das laterais e dos fundos dos lotes. Além do traçado, o novo arrabalde definiu áreas destinadas a hospital, jardins, bosques de eucaliptos, cemitério e capela. Brito elaborou com riqueza de detalhes uma sofisticada proposta de saneamento e de abastecimento d'água, bem como de drenagem acompanhada de aterro. O mesmo projeto ainda propunha medidas complementares, que incluía calçamentos, canais de contornos, limpeza pública de ruas e pátios, transporte e incineração do lixo, entre outras (LEME (coord.), 1999, p. 256-257).

Em síntese, o projeto para um novo bairro de Vitória apresentava detalhes de plantas e perfis da estrada de rodagem, do abastecimento de água, perfis de ruas e avenidas, tipos de canais de contorno, tipo de casa para o proletariado, dessecamento de mangues e terrenos, anteprojeto de esgoto, planta comparativa de terrenos secos e úmidos, brejos e mangues, planta de anteprojeto de drenagem, planta de arruamento e loteamento e planta da ilha de Vitória. O conjunto desse plano urbano demonstra uma maturidade em relação às questões urbanas e os diferentes elementos que constituiria uma cidade moderna. 


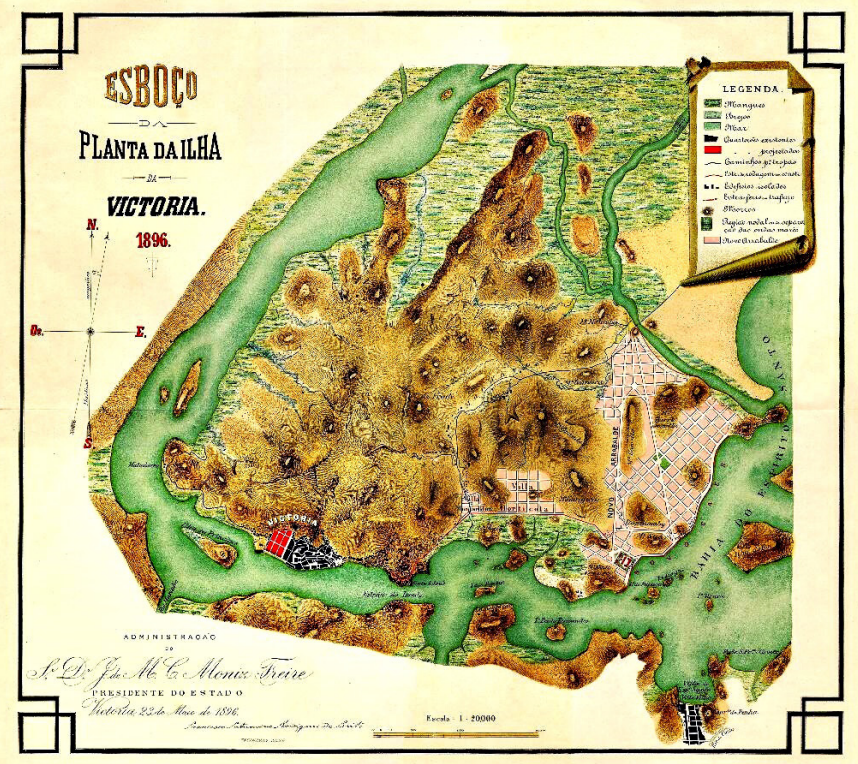

Figura 2 | Planta da llha de Vitória, 1896. À direita se pode observar o projeto do novo arrabalde para a cidade. Fonte: Prefeitura de Vitória. Disponível em: <http://legado.vitoria. es.gov.br/baiadevitoria/script/resulta do.asp\%C2\%BFp_arquivo=bcuna20\&tipo=data\&d ata $=1890$. html > ; acesso em: 29 set. 2018. 
Sob a dimensão do urbanismo sanitarista de Saturnino de Brito, pode-se elencar alguns pontos comuns que definem seu modo de atuação nas cidades: a necessidade de preparar anteriormente a construção das cidades visando atender aos requisitos de salubridade, como o ar, a luz e a circulação, por meio da proposição e implantação de um plano de melhoramentos urbanos; a reforma do poder público municipal e das competências técnicas para facilitar a defesa do interesse de todos; o conhecimento da área como um elemento fundamental para ações de transformação e construções urbanas. Para Brito, era preciso pensar a cidade como um todo, saneamento, áreas existentes e a serem habitadas, traçado e legislação.

\section{Saturnino de Brito e o projeto de abastecimento de água para Passo Fundo/RS}

O morador de uma cidade se defronta com uma série de necessidades vitais para a sua vivência. Ao implementar serviços urbanos para toda a coletividade, o poder público tem a incumbência de adotar algumas medidas. Essas medidas devem resultar de uma criteriosa análise prévia do problema específico e de suas implicações, e de sua melhor solução técnica e econômica, se constituem nos conjuntos de instalações e atividades conhecidas como serviços públicos urbanos. Segundo Ildefonso C. Puppi (1981, p. 213), há dois grupos dentro desses serviços: os 
que objetivam a salvaguarda da saúde pública, ou seja, o abastecimento de água, de esgotos, de coleta e remoção do lixo e limpeza pública; e há os de necessidade premente, ou seja, serviços que a municipalidade pode confiar a empresas particulares, tais como a geração e distribuição de energia elétrica, a distribuição de gás, etc.

$\mathrm{Na}$ estruturação sanitária das cidades, o fornecimento a toda a população de água de boa qualidade para o consumo, suficiente para todos os usos, é a finalidade de um sistema urbano de abastecimento. A qualidade e a quantidade da água são, pois, as duas condições primordiais a serem observadas. Embora se refira em particular à água da rede de distribuição, são fatores decisivos em todo o planejamento do sistema, a começar pela escolha da fonte de suprimento. Conquanto, somente a água potável, a que perfaz predeterminados requisitos físicos, químicos e bacteriológicos, tem garantia higiênica. É a única espécie a ser oferecida aos cidadãos, para todos os usos, mesmo para aqueles em que águas de qualidade inferior poderiam ser admitidos sem riscos sanitários (PUPPI, 1981, p. 215).

O manancial ou fonte para suprir o abastecimento de água, usualmente, é buscado entre os recursos hídricos da região. Os fatores decisivos para a escolha são: primeiro, a qualidade e a quantidade da água; depois, a distância e as implicações técnicas e econômicas. A hidrologia superfi- 
cial, por serem as águas naturais potabilizadas mais acessíveis, permitem um fácil e suficiente conhecimento do seu regime e favorecem a sua captação, é a mais cogitada e utilizada.

Para Ildefondo C. Puppi (1981, p. 219), as obras de captação se destinam a recolher do manancial a quantidade de água demandada para o abastecimento da cidade. Variam conforme as condições locais, hidrológicas, topográficas e, para as águas subterrâneas, hidrogeológicas. Esse processo visa à garantia de funcionamento, da qualidade (tomada a montante de focos de poluição, proteção sanitária, etc.) e economia das instalações (maior proximidade possível da cidade, favorecimento da adução por gravidade, dispensa ou simplificação do tratamento, facilitação das obras de captação, de adução, de recalque, etc.).

Ao analisar os recursos hídricos da cidade de Passo Fundo, localizada ao norte do estado do Rio Grande do Sul e distante $289 \mathrm{~km}$ da capital, Porto Alegre, as observações iniciais de Saturnino de Brito foram sobre a posição da cidade, isto é, sobre um divisor de águas, que torna a localidade exposta aos ventos frios no inverno e aos ventos frescos que amenizam os rigores do verão. Para o engenheiro, devido à situação altimétrica, o serviço de suprimento de água deveria ser decididamente onerado pela elevação mecânica. 
Saturnino de Brito (1943, p. 161) apontou em seus estudos que as duas grandes vertentes d'água, separadas pela Serra Geral, eram: a do rio Uruguai, a noroeste da cidade, e a do rio Jacuí, a sudoeste, correndo para a Lagoa dos Patos. Atendendo a linha sinuosa por onde correm as águas, que descem da cidade para os arroios, destacam-se três vertentes ou bacias para onde correm as águas pluviais saídas da cidade: a sueste desaguam duas sangas que desaguam no curso do Passo Fundo, o qual banha e limita a cidade ao nascente, e na direção noroeste corre a sanga Lava-Pés, formando a primeira das duas bacias de esgotamento pluvial para o Jacuí, ao sul; na direção leste, seguem duas sangas, que logo adiante se encontram formando um só curso d'água, pertencente à bacia hidrográfica do rio Jacuí.

Torna-se oportuno esclarecer que a bacia hidrográfica ou bacia de drenagem de um rio é a área de drenagem que contém o conjunto de cursos d'água que convergem para esse rio, sendo, a montante, limitada em superfície pelos divisores de água, que correspondem aos pontos mais elevados do terreno e que separam as bacias adjacentes. 0 conjunto de talvegues ${ }^{2}$, denominado de rede de drenagem, está estruturado, com todos os seus canais, para conduzir a água e os detritos que the são fornecidos pelos terre-

2. O talvegue é uma linha sinuosa, ao fundo de um vale, por onde correm as águas de um rio. 
nos da bacia de drenagem. "Bacia hidrográfica, portanto, é área, território dotado de declividade, que possibilita o escoamento das águas, que direta ou indiretamente se dirigem para um corpo de água central" (GORSKI, 2010, p. 43).

Saturnino de Brito (1943, p. 162) considerou o município de Passo Fundo afortunado, devido à riqueza em quedas d'água aproveitáveis para a distribuição da força elétrica. O engenheiro apontou a Usina Hidroelétrica Municipal, no rio Taquari, distante aproximadamente $21 \mathrm{~km}$ da cidade, para ser aproveitada para os serviços de iluminação e para as atividades industriais; possuía 20 metros de altura de queda e a descarga era, na época, de cerca de $3 \mathrm{~m}^{3}$ por segundo. Brito observou também o segundo degrau da queda do referido rio, com cerca de 27 metros de altura. A terceira riqueza era a cascata no rio Várzea, próxima à estação Carazinho, e a quarta era a cascata no rio Santo Antônio, próxima ao povoado do Campo do Meio, com 30 metros de altura.

A proposta para o abastecimento de água para a cidade de Passo Fundo tinha como objetivo resguardar a saúde da população e a higiene da cidade. O poder público na época se encontrava preocupado com os poços e latrinas que ficavam nos fundos dos quintais da cidade, situação que frequentemente contaminava as águas por meio de microrganismos que ali se proliferavam, causando a morte e ocasionando epidemias. 
Segundo Saturnino de Brito (1943, p. 172), havia em Passo Fundo um total de 1.000 casas abastecíveis de água na área urbana, com uma população de 6.000 habitantes, portanto, o volume correspondente a distribuir para o consumo em 12 horas deveria ser de $900 \mathrm{~m}^{3}$, a 150 litros por habitante e por dia, ou de $1.000 \mathrm{~m}^{3}$, a 1.000 litros por habitação e por dia. O projeto de expansão da cidade, proposto por Brito, permitia a edificação de mais 3.400 casas, cada uma em um lote de 15 a 20 metros de frente. O Engenheiro computou nesse número a edificação dessas moradias nos diversos terrenos baldios que ainda existiam na cidade de Passo Fundo. Mediante a soma, o total de casas era de 4.400, mas a previsão para o serviço de abastecimento de água a se executar nesse momento, a quantidade suficiente de água seria de 2.000 a $2.500 \mathrm{~m}^{3}$ para serem distribuídas nas 12 horas diurnas.

É interessante observar que Saturnino de Brito não propôs somente a abertura de novas ruas, no seu plano de meIhoramentos urbanos. O autor ponderou sobre as necessidades de aproveitar os terrenos baldios ao lado das ruas existentes e que, consequentemente, seriam beneficiados com os serviços de água e esgoto, por exemplo.

Como mencionado anteriormente, havia em Passo Fundo dois cursos d'água em condições de serem aproveitados para o abastecimento da cidade, à época. O rio Passo Fun- 
do seguia seu curso muito próximo da cidade, entretanto, mais à frente dela, ele bifurcava-se em dois grandes ramos (figura 3). Segundo Brito, foi feita a medição do volume de água pelo poder público municipal na época e registrou $8.000 \mathrm{~m}^{3}$ por dia. Até então o sistema empregado para a captação da água era o processo flutuador, ou seja, o respeito ao próprio movimento das águas. Na parte mais elevada da cidade, havia moradias e se tencionava fazer o aproveitamento da força hidráulica de uma pequena queda. O engenheiro observou que, para esse momento, poderia tomar a água de um só dos ramos do curso do rio, o serviço seria simples e a elevação seria de aproximadamente 60 metros de altura, em uma distância de $2 \mathrm{~km}$ da cidade, ficando o reservatório na cota topográfica de 722 metros, ou seja, a 8 metros apenas acima do ponto mais alto do núcleo urbano (BRITO, 1943, p. 172).

A solução descrita anteriormente não seria difícil de ser implementada, no caso de se aproveitar o referido manancial, era entrar em acordo com uma usina de mate para aproveitar a queda d'água. A água distribuída na cidade, uma boa parte dela, voltaria ao curso como fluente da depuração dos esgotos, situação oportuna, pois o poder público tinha à disposição a força elétrica barata para substituir a pequena força da roda hidráulica da usina. Conquanto, mesmo com esse estudo, Brito optou no projeto por uma outra solução: o curso do rio Miranda, distante aproximadamente $5 \mathrm{~km}$ do 
rio Passo Fundo. Possivelmente a escolha sobre esse rio recaiu pelo fato de ele estar em uma região de campos e as residências estarem distantes de suas margens, mantendo a qualidade de suas águas e a preservação das matas.

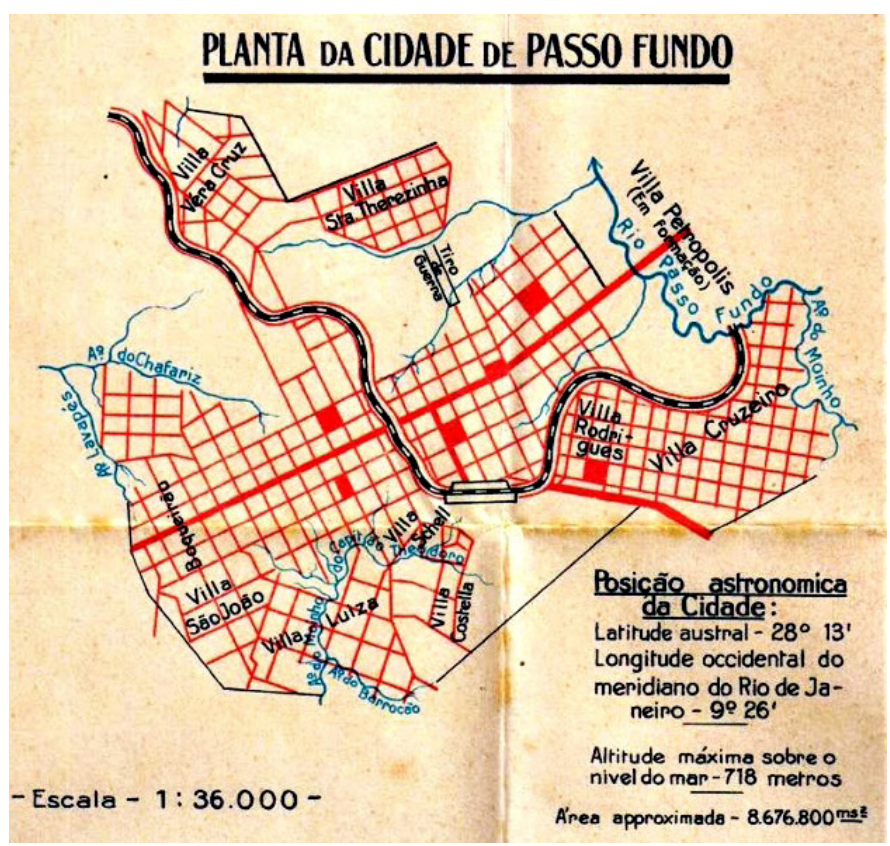

Figura 3 | Planta da cidade de Passo Fundo, s/d. Avaliou-se que esta planta foi elaborada décadas depois da presença de Saturnino de Brito em Passo Fundo, mas a partir dela é possível observar os cursos d'água da cidade. No alto, à direita, destaca-se o rio Passo Fundo. Fonte: Coletânea de Dados sobre Passo Fundo. Disponível em: <https://martinellilucia.blogspot.com/2016/10/passinho_40.html>; acesso em: 29 set. 2018. 
Saturnino de Brito, em seus projetos, sempre procurou dar atenção à morfologia dos leitos fluviais, propondo a preservação das matas, a proteção das cabeceiras e, quando a devastação já tivesse ocorrido, propunha o replantio da área, criticando a retificação de canais. Argumentava que a intervenção nos leitos, retificando-os, poderia ocasionar inundações, e propunha barragens nas cabeceiras para controle da ação das chuvas torrenciais. "Quanto às redes de esgotos, defendia que deveriam ser bem vedadas, para impedir poluição do ar e do solo, sendo que a rede de coleta de águas pluviais deveria ter tubulação separada" (GORSKI, 2010, p. 83).

A preocupação com as questões ambientais, especialmente com os cursos d'água, sempre esteve presente em suas obras. Brito (1943, p. 170) alertava que essa preocupação deveria ser de todos. Para ele, era preciso estudar o potencial das quedas d'água, para que se pudesse garantir descargas elétricas para as cidades. Era importante esgotar todos os recursos que as águas podem oferecer, tais como: retirar das águas das chuvas e das águas correntes o melhor proveito que podem oferecer. Elas ainda poderiam se constituir em recursos agrícolas, pela irrigação, além de se constituírem em força econômica, poupando combustíveis fósseis.

No seu projeto para Passo Fundo, Saturnino de Brito res- 
salta a importância de realizar o tratamento de purificação das águas para abastecimento. $\mathrm{O}$ engenheiro revela que a municipalidade deveria desapropriar determinadas áreas próximas para a proteção do curso. Uma vez desapropriadas, o poder local deveria transformá-las em um bosque para proteção e lazer dessas regiões.

Para a captação das águas do rio Miranda, Brito apresentou duas soluções. A primeira considerava a tomada das águas em uma pequena represa na cota 673. A barragem teria 4 metros de altura, assim o nível subiria até a cota de 677,20. Com a água nesse nível, receberia uma dose de cal para ser decantada, seguiria por um aqueduto até uma altura de 5 metros para filtração, não sendo suficiente essa altura, o aqueduto se prolongaria por mais 400 metros, para alcançar mais 3 metros, isto é, 8 metros no total. Conforme o projeto, essa primeira solução apresentava algumas vantagens: a água passaria limpa no conduto emissor; o trabalho de filtração seria contínuo, durante as 24 horas, e o trabalho de elevação mecânica poderia ser intermitente. Assim, bastaria dar aos filtros a capacidade de 25 litros por segundo, ou $1.080 \mathrm{~m}^{3}$ em 12 horas. Segundo o sanitarista, "a bomba, tendo a capacidade para elevar 50 litros por segundo, trabalhará 12 horas, no presente. Mais tarde será fácil aumentar a capacidade de filtração e bastará aumentar o número de horas de trabalho da bomba" (BRITO, 1943, p. 175). 
A segunda solução consideraria a captação das águas na cota 667,50, o que significava que a represa teria apenas 3 metros de altura. A água tratada com cal, por meio de aparelhagem hidráulica, passaria por uma caixa de decantação e seria recebida no poço de aspiração pela bomba, para ser elevada e depositada em tanque descoberto, área situada na cota topográfica 734 .

O processo de filtração aconteceria de maneira diferente nessas soluções. Na primeira solução, Brito propôs como filtração das águas o emprego de determinados tipos de filtros. Esses filtros fabricados facilitariam o processo por meio da gravidade, pois exigiriam menor altura que os trabalhados sob pressão. "Para o caso parece-nos que serão bem indicados os tipos de seis pés de diâmetro, trabalhando sob pressão; eles dão $500 \mathrm{~m}^{3}$ em 24 horas e seriam precisas seis unidades, para se ter alguma folga na capacidade de produção" (BRITO, 1943, p. 177).

Para a segunda solução, esses filtros ficariam juntos aos reservatórios e a própria fábrica indicaria a altura necessária para se alcançar a pressão devida. Nesse caso, poderiam ser empregados filtros que permitiriam uma filtração de $900 \mathrm{~m}^{3}$ em 24 horas.

Saturnino de Brito revelou que era com receio que projetava a filtração rápida das águas para as pequenas cidades, já 
que ela exigia a adição de coagulantes periodicamente, dispondo de um funcionário competente a se dedicar a esse tipo de serviço.

Quanto à elevação mecânica das águas, Brito propôs para as duas soluções de captação a elevação mecânica. No caso da primeira solução, a água seria bombeada de um reservatório para outro da cidade. No caso da segunda solução, a água seria elevada da cota topográfica 670 para a cota 734. Segundo o engenheiro, tem-se "quase a mesma diferença de nível e, assim, podemos dar uma única solução ao problema da elevação mecânica" (BRITO, 1943, p. 179).

É importante destacar que o projeto de Saturnino de Brito para Passo Fundo dividiu a cidade em três zonas, isto é, áreas para abastecimento de água. Entretanto, como o próprio engenheiro ressalta, "esse plano não obedece a limites precisos, no ponto de vista altimétrico" (BRITO, 1943, p. 180). A zona de número 1 seria a parte mais alta da cidade e seria alimentada pelo Reservatório R.1. A zona de número 2 compreenderia a parte baixa e seria abastecida pelo reservatório R. 2, situado na cota topográfica 714. A zona de número 3, a Vila "F", denominada assim na época, hoje Vila Rodrigues, seria alimentada pelo reservatório R.3, na cota 722, e uma parte pelo reservatório R.1 (BRITO, 1943, p. 180) (figura 4). Segundo os estudos de Saturnino de Bri- 
to, os reservatórios R.2 e R.3 seriam construídos em um futuro próximo, como aponta o projeto, e passariam a ser alimentados por um conduto que convergiria do reservatório R.1.

Conforme aponta Donatella Calabia (2012, p. 81-89), quando discute sobre as condições sanitárias das cidades europeias, a história desse período é essencial para se entender o contexto da mudança, representado pelas relações entre poder central e poder local, e pela maneira como os acontecimentos políticos influíram na vida urbana. Por meio de análises conduzidas minuciosamente sobre o corpo "enfermo" da cidade, as medidas sanitárias tiveram condições de esclarecer quais eram os problemas das áreas mais degradas e do subsolo, permitindo se elaborar instrumentos que pudessem revelar até mesmo o que não era visível aos olhos humanos. As amostras de águas potáveis, as inspeções de fossas e de habitações permitiriam reorganizar os direcionamentos dos espaços urbanos. A exigência para se fornecer água potável para cada casa, a construção de edifícios saudáveis e confortáveis, a ampliação e o endireitamento das ruas foram fatores determinantes para a modernização das cidades. 


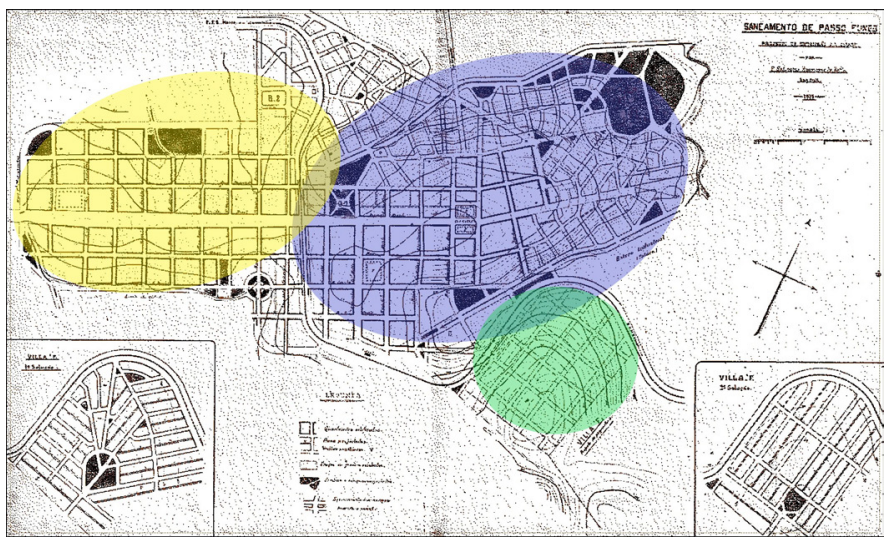

Figura 4 | "Saneamento de Passo Fundo," 1919, elaborado por Saturnino de Brito. Nesta figura, as áreas de abrangência dos três reservatórios são interpretadas. Em azul, destaca-se a área aproximada do reservatório R.1; em amarelo, a área do reservatório R.2; e em verde, a área do reservatório R.3. Fonte: BRITO, 1943, p. 163. 


\section{Considerações Finais}

A consciência por parte da população da dependência e da finitude dos recursos naturais, como a água, por exemplo, é fator relevante de valorização e envolvimento, no sentido de se preservar, conservar ou recuperar, no caso dos arroios e dos mananciais de abastecimento urbano. Uma nova dimensão de valores está sendo desperta.

Os recursos hídricos atuam como coadjuvantes de diferentes elementos para a conformação da paisagem natural e cultural, como a topografia, solo, modelagem do relevo, vegetação. Assim, pode-se observar que as paisagens fluviais foram sendo apropriadas como paisagens urbanas que favorecem na circulação de bens e pessoas, energia e lazer. Analisar a paisagem urbana por intermédio de seus recursos hídricos possibilita um entendimento mais amplo do território.

A problemática ambiental nas cidades, em especial dos recursos hídricos, não pode ser desvinculada da dinâmica de produção do espaço urbano, sendo que, ao gerar impactos negativos na qualidade de vida urbana de várias ordens (social, cultural e ambiental), afeta, com distribuição desigual de riscos, toda a população urbana. Dentro dessa conjuntura, está a questão da qualidade do abastecimento e das águas. 
Essa preocupação ambiental não é uma discussão do presente. A modernização das cidades e a fase de insalubridade urbana, articulando preocupações com os mananciais d'água e a infraestruturação do processo de abastecimento, datam de um passado recente, o início do século XX, tendo o engenheiro sanitarista Francisco Saturnino Rodrigues de Brito como expoente. Como bem discutido, o seu ideário urbano e sanitarista destacava a importância de um sistema de condução do esgoto por duto exclusivo, separado do de águas pluviais. As águas não poderiam ser contaminadas.

A proposta de Saturnino de Brito para a cidade de Passo Fundo revela a sua preocupação com as questões ambientais, por exemplo, com a mata ciliar, com o curso dos rios e aproveitamento natural da força das águas em queda, além de sua filtração para uso diário da população. Destaca-se também a preocupação do engenheiro em informar e educar os cidadãos para as questões relativas ao meio ambiente. Com esse projeto, Brito aliou ao embelezamento da cidade o saneamento, considerando a perspectiva de proteção do patrimônio natural presente na cidade. Essa dimensão corrobora a confirmação da hipótese levantada para este estudo.

Como já mencionado, o projeto não foi implementado, entretanto foi argumentado que esse saber veiculou entre as 
autoridades públicas da época, dessa forma, considera-se que o obstáculo para a construção de uma cidade melhor não é a falta de conhecimento, mas o consentimento em não aplicar esse conhecimento.

\section{Referências}

ANDRADE, Carlos Roberto Monteiro de. O plano de Saturnino de Brito para Santos e a construção da cidade moderna no Brasil. Espaço \& Debates, São Paulo: NERU, n. 34, p. 55-63, ano XI, 1991.

ANDRADE, Carlos Roberto Monteiro de. A peste e o plano: 0 urbanismo sanitarista do Engenheiro Saturnino de Brito. São Paulo: USP, 1992. Dissertação (Mestrado em Estruturas Ambientais Urbanas) - Faculdade de Arquitetura e Urbanismo, Universidade de São Paulo, 1992.

BERNARDINI, Sidney Piochi. A dureza do fazer. A práxis na urbanística de Saturnino de Brito a partir do seu plano de saneamento para a cidade de Santos (1905-1910). Revista Risco, São Carlos, n. 22, p. 47-62, 2015.

BERTONI, Angelo. A engenharia sanitária a serviço do urbanismo: a contribuição de Saturnino de Brito e Victor da Silva Freire para a construção dos saberes urbanos. Revista Risco, São Carlos, n. 22, p. 74-83, 2015.

BURGER, Juliana Bandeira A. A paisagem nos planos de saneamento de Saturnino de Brito: entre Santos e Recife (1905-1917). Dissertação (Mestrado), Universidade Federal de Pernambuco, Recife, 2008.

CALABI, Donatella. História do urbanismo europeu: questões, instrumentos, casos exemplares. São Paulo: Perspectiva, 2012.

CARRIÇO, José Marques. O plano de Saturnino de Brito para Santos: urbanismo e planejamento urbano entre o discurso e a prática. In: CAMPOS, C. de; ATIQUE, F; DANTAS, G. A. F. (orgs.). Profissionais, Práticas e Representações da Construção da Cidade e do Territó- 
rio. São Paulo: Alameda, 2013.

DANTAS, Ana Carolina de Carvalho Lopes. Sanitarismo e planejamento urbano: a trajetória das propostas urbanísticas para Natal entre 1935 e 1969. Dissertação (Mestrado) - Universidade Federal do Rio Grande do Norte, Natal, 2003.

DEMINICl, Daniel. As águas do rio Pardo são puríssimas. Saturnino de Brito nas polêmicas sobre os mananciais de Ribeirão Preto. Revista Risco, São Carlos, n. 22, p. 102-119, jul-dez. de 2015.

DIEB, Marília de Azevedo. Contribuições do trabalho de Saturnino de Brito à leitura das águas urbanas brasileiras no final do século XIX e início do século XX e suas repercussões na construção da paisagem urbana e na proteção dos corpos d'água e recursos hídricos. Revista Risco, São Carlos, n. 22, p. 63-73, jul-dez. de 2015.

GITAHY, Maria Lúcia. Caira. Estudos de história e fundamentos sociais da arquitetura e do urbanismo em São Paulo. In: GITAHY, M. L. C. (org.). Desenhando a cidade do século XX. São Carlos: RiMA, Fapesp, 2005.

GORSKI, Maria Cecília Barbieri. Rios e cidades: ruptura e reconciliação. São Paulo: Editora Senac São Paulo, 2010.

LEME, Maria Cristina da Silva (coord.). Urbanismo no Brasil - 1895 1965. São Paulo: Studio Nobel; FAUUSP; FUPAM, 1999.

LOPES, André Luís Borges. "Sanear, prever e embelezar": o engenheiro Saturnino de Brito, o urbanismo sanitarista e o novo projeto urbano do PRR para o Rio Grande do Sul (1908 - 1929). Tese (Doutorado) - Faculdade de Filosofia e Ciências Humanas da Pontifícia Universidade Católica do Rio Grande do Sul, Porto Alegre, 2013.

BRITO, Saturnino de. Ministério da Educação e Saúde. Projetos e relatórios: saneamento de Santa Maria, Cachoeira, Passo Fundo, Rosário e Cruz Alta. Obras Completas de Saturnino de Brito, v. XI. Rio de Janeiro: Imprensa Nacional, 1943.

PUPPI, Ildefonso C. Estruturação sanitária das cidades. Curitiba: Universidade Federal do Paraná; São Paulo, CETESB, 1981.

SIMÕES JUNIOR, José Geraldo. O ideário dos engenheiros e os planos realizados para as capitais brasileiras ao longo da Primeira República. In; CAMPOS, C. de; ATIQUE, F.; DANTAS, G. A. F. (orgs.). 
Profissionais, práticas e representações da construção da cidade e do território. São Paulo: Alameda, 2013.

TOCHETTO, Daniel. A cidade de Santa Maria e o saneamento de Saturnino de Brito. Dissertação (Mestrado em Planejamento Urbano e Regional), Faculdade de Arquitetura e Urbanismo da Universidade Federal do Rio Grande do Sul, Porto Alegre, 2013.

Agradecimentos:

Agradecemos a Fundação Meridional - IMED, Passo Fundo/RS, pelo apoio irrestrito ao desenvolvimento deste presente trabalho.

Recebido em: 01/07/2018

Aprovado em: 31/07/2018 